\title{
Arq in ars. La arquitectura en el arte medieval
}

\author{
Tamara Corrales Fernández \\ Universidad de Lima, Perú
}

Recibido: 16 de mayo de 2014 / Aprobado: 11 de julio de 2014

Si bien la arquitectura y el arte han tenido una estrecha relación como constructores de la cultura humana a lo largo de los años, ambos se han desarrollado tanto en el campo técnico como en el creativo. Las relaciones que se presentan entre ambas disciplinas pueden ser contrastadas o interpoladas a partir de la aparición del uno en el otro. En este caso, veremos de qué manera la arquitectura aparece en el arte, que al desarrollar la técnica pictórica y de composición, da una vitrina mayor a la aparición de la arquitectura como uno de los protagonistas del mensaje que se quiere expresar, determinando así épocas, estilos e inclusive situaciones específicas.

arquitectura, arte, Edad Media, gótico, románico

\section{Arq in ars. Architecture in medieval art}

Although the architecture and art have had a close relationship as builders of human culture over the years, both have developed in the technical and creative field. The relationships that exist between the two disciplines can be contrasted or interpolated from the appearance of one into the other. In this case, we will see how the architecture appears in the art, that in developing of the pictorial and compositional technique, gives greater showcase the emergence of architecture as one of the protagonists of the message you want to express, determining times, styles and even specific situations.

architecture, art, middle age, gothic, romanesque 


\section{INTRODUCCIÓN}

En el análisis de la historia del arte se encuentra un área de especial interés para los arquitectos: la representación arquitectónica. En ella se ha visto la necesidad de representar el medio dentro de la composición para darle sentido al mensaje: es distinto dos hombres luchando frente a un campo que frente a un castillo medieval. Dentro de esta representación se ubica el medio arquitectónico o medio construido, representar edificaciones o interiores completan el mensaje, y llenan la obra con armonía y balance para entender mejor la idea, es un recurso válido como fondo y como contexto.

En este ensayo se tratará de explicar la evolución de estas representaciones arquitectónicas en los diferentes periodos de la historia, reconociendo sus distintas características, limitantes y su evolución. Se comenzará explicando el periodo bizantino, seguido del periodo románico, y se finalizará con el periodo gótico. Se tendrán en cuenta características como la perspectiva, la luz, la sombra, la escala, entre otras.

\section{PERIODO BIZANTINO}

El arte bizantino surge gracias a la evolución del arte paleocristiano, tomando en cuenta los rasgos más resaltantes de la cultura greco-latina y las influencias provenientes de Oriente y de Occidente. El papa Gregorio consideraba,en ese entonces, elarte como un objeto útil, puesto que este enseñaba a los analfabetos las obras de Dios y de Jesús, por lo que aquellas representaciones artísticas tenían que ser sencillas y claras. Por eso, todos los detalles eran omitidos para no quitarle importancia al mensaje sagrado. Así, con el tiempo este tipo de arte se fue concentrando poco a poco en lo esencial, representándolo de la manera más simbólica posible. Esto hacía que el espectador entendiera y relacionara mejor las imágenes de las distintas obras, según los símbolos establecidos y conocidos por la Iglesia. Los artistas de este periodo no plasmaban sus obras en cuadros, sino en mosaicos compuestos por pequeñas teselas que decoraban los interiores de las iglesias, mayormente de colores brillantes y fondos dorados.

Con respecto a las representaciones arquitectónicas en estos mosaicos, a pesar de no concentrarse en los detalles y el fondo o contextos - ya que lo importante era centrarse en el mensaje- hay cierto intento, no del todo correcto, de perspectiva; aunque siguen siendo fondos planos. También la luz plana y la carencia de sombras hacen que sea menos realista, las escalas estaban mal manejadas en esta época. Estos factores influyen en el sentido de profundidad, prácticamente nulo, presente en las representaciones de este periodo.

En la figura 1 se puede observar la mano de Dios, que vive en los cielos, recibiendo las ofrendas que le son hechas; se puede ver un intento de perspectiva, porque se dieron cuenta de que las cosas, las personas y las edificaciones se ven ligeramente torcidas según la posición del espectador; sin embargo, aún no sabían la técnica que tenían que utilizar para poder realizar el efecto de perspectiva. También se nota una gran desproporción con respecto a los edificios

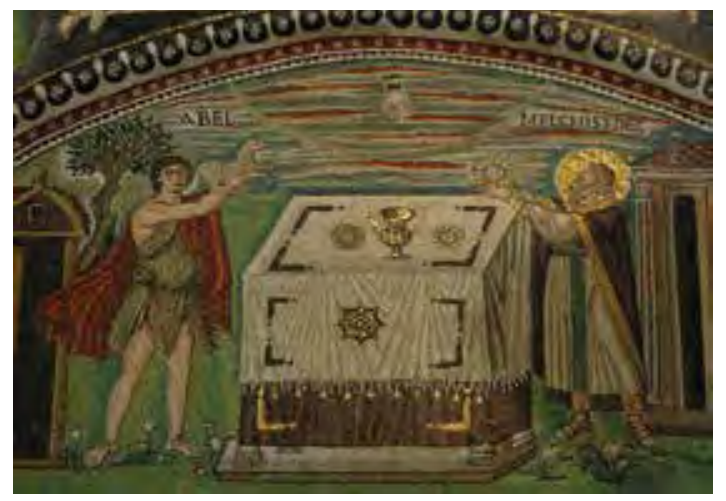

Figura 1

El sacrificio de Abel y Melquisedec.

Fuente: www.platytera.blogspot.com 
presentes en el mosaico bizantino, donde se intenta aplicar técnicas de luz apropiadas pero sin éxito.

Además, se puede apreciar (figura 2) el intento de perspectiva, gracias a las tejas del techo que parecen apuntar a un punto en común o punto de fuga; se puede llegar a diferenciar dos planos de profundidad ligeramente mejor trabajados, donde gracias a la escala unas edificaciones se ven más alejadas que otras.

\section{PERIODO ROMÁNICO}

Este siguiente periodo se dio en los siglos XI al XIII, como consecuencia de la influencia religiosa. Esta etapa, a diferencia del bizantino, no fue influenciada por las características greco-latinas y orientales, sino que hubo un retroceso en la tecnología porque la Iglesia imponía una actitud de "anti-conocimiento", como consecuencia, su arte fue más burdo y tosco. La búsqueda del conocimiento y la ciencia eran consideradas un rito pagano y por este motivo era censurado. El arte románico es simbólico, cada detalle de representaciones era estudiado según su mensaje y su sentido para que los espectadores pudieran relacionar las diferentes obras que tenían los

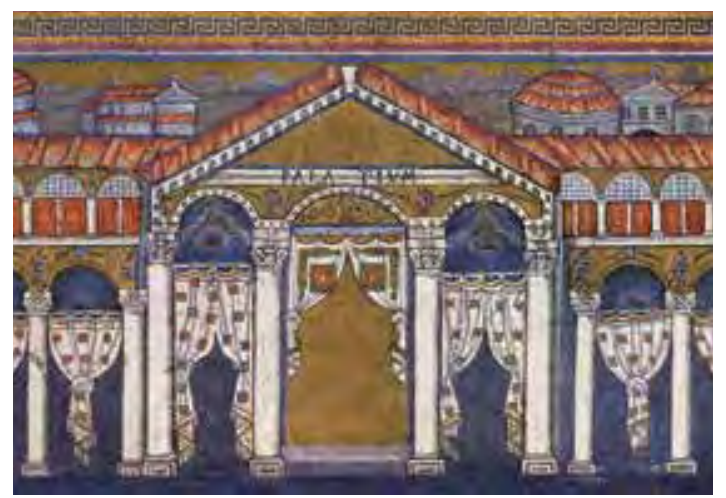

Figura 2.

Palacio de Teodorico.

Fuente: www.wikipedia.org ISBN 393612202 mismos símbolos. Estas representaciones eran rígidas e inexpresivas como los relieves egipcios, y eran de poca complejidad; sin embargo, con el transcurso del tiempo va apareciendo un nivel comunicación e interacción entre las personas representadas. Se buscaba informar no por medio de palabras, sino mediante ilustraciones claras que eran intensas y con grandes contrastes cromáticos, así, era más fácil saber qué representan y se ajustaban mejor al edificio. Los artistas concebían sus obras de acuerdo con la arquitectura.

Las representaciones arquitectónicas eran planas y simples y no muestran ningún intento de perspectiva, puesto que no era el centro de la preocupación la representación general, sino un acompañamiento de fondo para relacionar al espectador con el mensaje que transmite y sentir que es parte de él. La ausencia de luz y la desproporción de escalas no ayudan a que haya una profundidad notoria, al igual que en el periodo bizantino.

El mal manejo de la escala se puede ver claramente en la figura 3, donde no hay planos ni sentido de profundidad con respecto a las edificaciones representadas. Este fragmento del tapiz de Bayeux intenta transmitir, antes de todo, un mensaje sobre un momento específico en la historia que sería el paso de una estrella fugaz, mientras que los edificios que se encuentran en este tapiz son dejados en un segundo plano.

Otro caso sería el de la figura 4, donde se ve que el fondo arquitectónico es dejado de lado y puesto en un segundo plano, ya que lo importante en esta época era transmitir el mensaje esencial que en este caso sería la pelea entre los soldados. El fondo sirve para expresar mejor la historia representada, la escala de la torre con respecto a las personas es incorrecta, pero cumple su propósito de comunicar lo necesario: el contexto donde ocurre el conflicto. 


\section{PERIODO GÓTICO}

Este periodo abarcó desde el siglo XII hasta el siglo XVI, y surge gracias a la evolución del arte predecesor, el románico. $\mathrm{El}$ arte de este periodo se interesa más por el naturalismo y las emociones, es simbolista, con mucho detalle, y además cuenta con mucho movimiento y colores. Se caracteriza también por la estilización de las figuras, el uso de líneas curvas, especialmente en los ropajes. La finalidad del artista gótico era representar el tema sagrado o una anécdota de la manera más emotiva y natural posible. Además de su carácter simbólico, el arte era utilizado para adoctrinar a las personas, y como medio decorativo, por ello era muy común la aparición de los vitrales para decorar las iglesias; al final de este periodo se dio un salto del simbolismo al realismo.

En este periodo las representaciones arquitectónicas ya contaban con una perspectiva correcta, que va perfeccionándose con el paso del tiempo; hay un uso adecuado de la luz y de la sombra, que

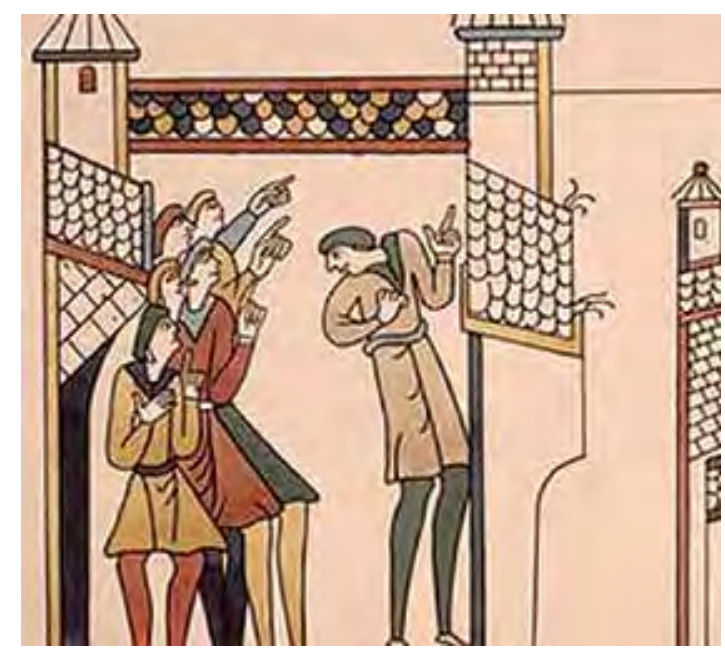

Figura 3

Tapiz de Bayeux.

Fuente: www.wikipedia.org le da profundidad a la escena representada. Las edificaciones se usan junto con el fondo general para darle un tiempo y un lugar específico en la historia y que se entienda mejor el mensaje que se quiere transmitir. La arquitectura ya no queda en un segundo plano, como en el periodo románico; además, la escala está, en la mayoría de los casos, bien proporcionada, lo que le da mayor realismo a la obra.

En la figura 5, donde se representa la flagelación de Jesús, se observa una mejor perspectiva, en la cual ya se usa la luz y la sombra para darle profundidad a la escena y donde las casas del fondo comunican que la escena sucede en la vía pública. La arquitectura de fondo ya no es solo decorativa, ahora sirve para entender mejor el mensaje; la escala aún no es perfecta pero va mejorando, hay un mejor trabajo en los detalles en comparación con las épocas anteriores.

En la figura 6 se puede ver una perspectiva casi perfecta, con un buen uso de la luz y de la sombra

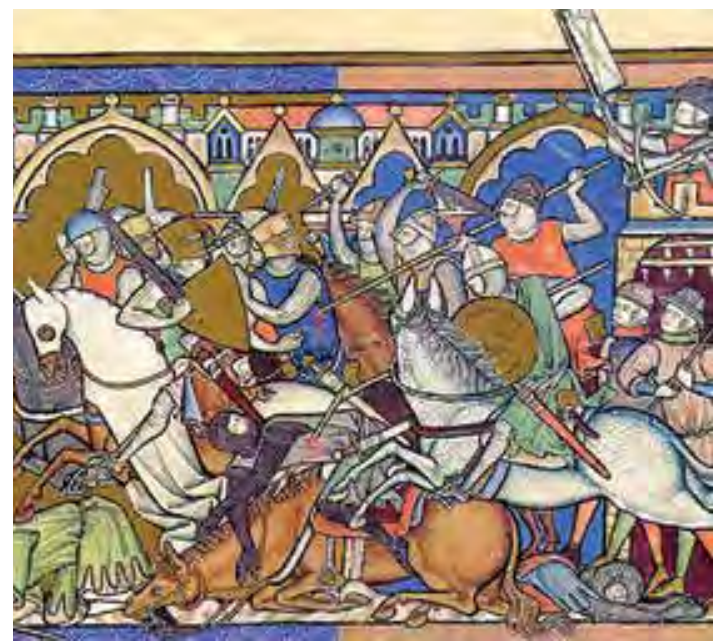

Figura 4

Figura de la Biblia de Morgan.

Fuente: www.wikipedia.org 
que hace que haya una profundidad notoria, la escala es adecuada e irá mejorando con el paso del tiempo. Ahora la arquitectura ya no es parte de un fondo sino de la escena en general, se le da mayor importancia y se le pinta con mucho más detalle que en los periodos pasados.

\section{COMPARACIÓN}

Se puede ver una gran evolución si comparamos las figuras 1 y 2 , que pertenecen al periodo bizantino, con la figura 5 , que es de la época gótica; la perspectiva cambia notoriamente, de ser plana y con una escala realista a generar una profundidad trabajada con luces y sombras, con una escala casi perfecta. Son casi diez siglos los que demoró tener un manejo adecuado de la perspectiva en el aspecto arquitectónico. El uso de colores más naturalistas también es parte de la evolución y el cambio que ocurrió en todos esos siglos. En la figura 3 del periodo románico

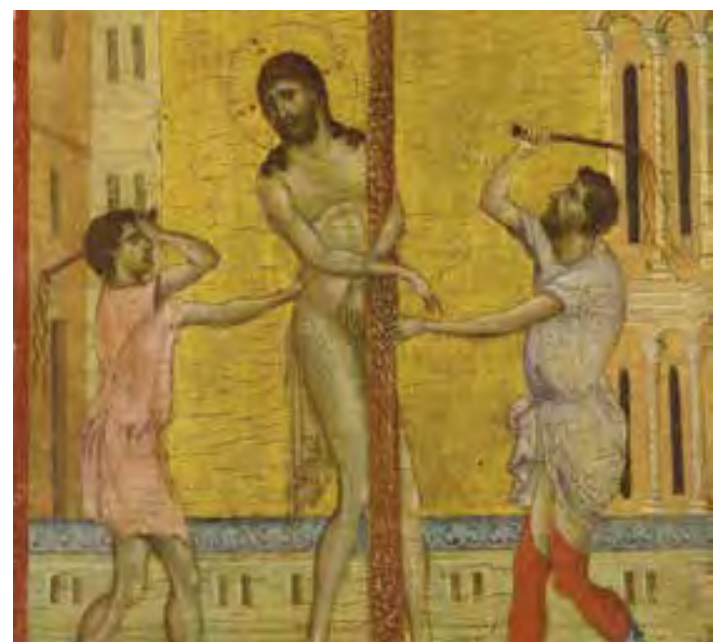

Figura 5

Flagelación. Cimabue.

Fuente: www.wikipedia.org ISBN 978-27-4271-925-9 se ve que la arquitectura representada es dejada de lado si se compara con figura 6 del periodo gótico, la escena sucede en las afuera de una casa, donde se puede ver que las representaciones arquitectónicas toman más importancia con el paso de los siglos y ya no son solo sirven de fondo o para entender mejor el mensaje, ahora forman parte de la escena y se les pone más atención y esfuerzo para lograr que tengan perspectiva, sombras, luces y escala.

\section{CONCLUSIÓN}

En conclusión, las representaciones arquitectónicas no eran importantes en el periodo bizantino, se le daba más importancia al mensaje y al simbolismo para educar a los iletrados. Estas representaciones no tenían un intento de perspectiva (que no estaba del todo lograda), la escala era incorrecta y representaciones eran planas; en el periodo románico, el arte era más burdo y tosco por las actitudes

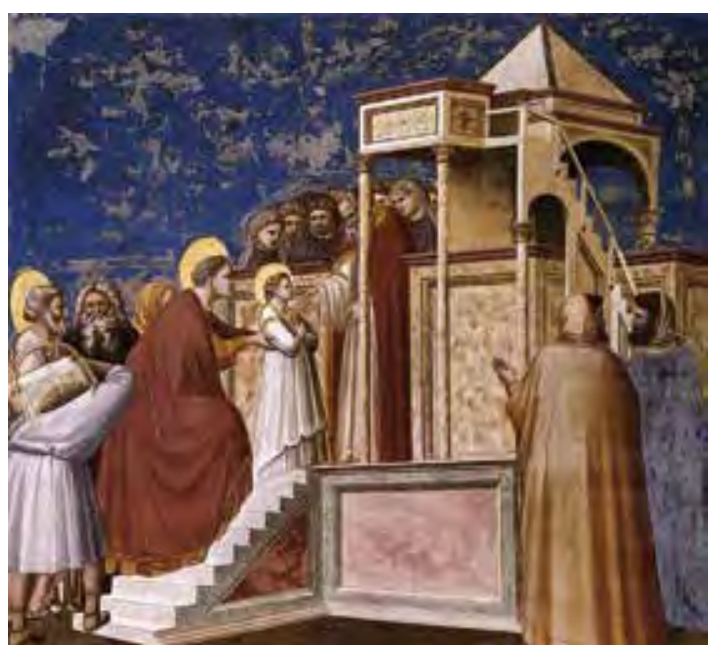

Figura 6.

Presentación de la Virgen en el templo. Giotto. Fuente: www.wikipedia.org 
"anticonocimiento" que proponía la Iglesia; no había intentos de perspectiva y las representaciones quedaban relegadas por las acciones, que eran más importantes porque transmitían un mensaje; en el periodo gótico el arte además de ser didáctico era decorativo, se dio más importancia a los fondos arquitectónicos en la medida en que estos eran parte de las escenas representadas y se entendían mejor la perspectiva y la escala.

Entonces, se puede decir que las representaciones arquitectónicas en las pinturas, mosaicos y obras artísticas en general son importantes por la ubicación y el tiempo que brinda a muchas escenas o anécdotas, porque les da mayor realismo y las vuelve más comprensibles y didácticas. Por eso, con el paso de los siglos, los artistas se dieron cuenta de su importancia y comenzaron a enfocarse en ellas para poder expresar mejor sus ideas.

Encontramos, en la primera parte de este análisis, una representación básica del medio construido que no era considerado importante, aunque de todas maneras se buscaba su inclusión, pues es la importancia del contexto que lleva a los artistas a mejorar sus representaciones explorando la escala, la perspectiva, la luz, entre otros elementos.

Más adelante, en el periodo románico, la exclusión del detalle y el retroceso, tanto artístico como científico, llevarían a pensar que la representación arquitectónica sería dejada de lado pero aun así se siguió explorando hasta llegar a un mejor entendimiento de la escala.

No es sino hasta el periodo gótico en que el medio deja de ser solo un fondo y se convierte en elemento ornamental, que embellece las obras artísticas, gracias a la escala y perspectiva mejoradas; los colores y las técnicas utilizadas muestran el desarrollo no solo del arte y la belleza, sino también del conocimiento científico, el cual le dio pase al arte posterior.

\section{REFERENCIAS}

Artehistoria. (s. f.). Recuperado de www. artehistoria.com.

Gombrich, E. (2010). Historia del arte. Madrid: Debate. 